\title{
Proizvodnja voćnog i loznog sadnog materijala u 2017. godini u Hrvatskoj
}

\author{
Production of fruit and vine planting material \\ in 2017 in Croatia
}

\author{
K. Brus, Kristina Horvat - Budimir
}

\section{SAŽETAK}

Proizvodnju voćnog i loznog poljoprivrednog sadnog materijala u 2017. godini za stručni nadzor Hrvatskom centru za poljoprivredu, hranu i selo, Zavodu za sjemenarstvo i rasadaničarstvo prijavilo je 60 rasadnika voćnih sadnica i 15 rasadnika loznih cijepova.

Ukupno je prijavljeno 4.394.442 voćnih sadnica i 3.057.226 loznih cijepova, što predstavlja blagi porast količine proizvodnje voćnog i loznog sadnog materijala. Ukupno su u proizvodnji 31 voćna vrsta i 69 sorti vinove loze. U prijavljenoj strukturi proizvodnje voćnih sadnica najviše su zastupljene jabuke sa $36,01 \%$ i lijeska sa $20,11 \%$, a zatim masline $(6,42 \%)$, kruške $(5,76 \%)$, višnje $(4,68 \%)$, trešnje $(3,82 \%)$, šljive $(3,65 \%)$, itd. Od ukupne prijavljene količine voćnih sadnica $15 \%$ su sadnice certificirane kategorije, dok je od ukupne prijavljene količine loznih cijepova certificiranih $54 \%$.

Ključne riječi: sadni materijal, voćne sadnice, lozni cijepovi

\section{SUMMARY}

In the 201760 fruit and 15 grape vine nurseries have applied for official inspection of nursery production to Croatian Centre for Agriculture, Food and Rural Affairs, Institute for Seeds and Seedlings. 4.394 .442 of fruit plants (33 species), and 3.057.226 of grape vine plants (69 varieties) have entered the sistem of official inspection which represents a minor increasing trend in fruit and vine planting material production. The largest part in production of fruit planting material are apples $(36.01 \%$ of total fruit species), followed by hazelnuts $(20.11 \%)$, olives $(6.42 \%)$, pears $(5.76 \%)$, cherries $(4.68 \%)$, sweet cherries $(3.82 \%)$, plums (3.65\%), etc.

$15 \%$ of the fruit plants and $54 \%$ of grape vine plants in the system of official inspection of nursery control were category "certified".

Key words: planting material, fruit plants, grape vine plants 


\section{UVOD}

Republika Hrvatska ima dugu tradiciju proizvodnje voćnog i loznog sadnog materijala, a kretanje proizvedene količine varira iz godine u godinu.

Sukladno propisima, Zakonu o sjemenu, sadnom materijalu i priznavanju sorti poljoprivrednog bilja (NN 140/05; 35/08; 55/11; 14/14), Pravilniku o stavljanu na tržište reprodukcijskog sadnog materijala i sadnica namijenjenih za proizvodnju voća (NN 09/2017), Pravilniku o stavljanju na tržište materijala za vegetativno umnažanje loze (NN 133/06; 67/10; 30/11; 77/13) i Pravilniku o postupku stručnog nadzora i nadzora pod stručnom kontrolom nad proizvodnjom poljoprivrednog reprodukcijskog materijala (NN 144/09; 30/11; 50/11), Hrvatski centar za poljoprivredu hranu i selo - Zavod za sjemenarstvo i rasadničarstvo je kako proteklih godina, tako i tijekom 2017. godine organizirao i provodio nadzor nad proizvodnjom voćnih sadnica, loznih cijepova te reprodukcijskog materijala voćnih vrsta i vinove loze.

Kada govorimo o proizvodnji voćnih sadnica, obavljen je stručni nadzor i nadzor kritičnih točaka u proizvodnji, te su dobiveni podaci o cjelokupnoj proizvodnji prijavljenih voćnih sadnica po vrstama, sortama i tipovima podloga.

Osam dobavljača prijavilo je proizvodnju voćnih sadnica viših kategorija i kod njih je obavljen stručni nadzor kojim je utvrđeno da propisanim uvjetima kakvoće zadovoljavaju 479.459 kom voćnih sadnica certificirane kategorije.

Nadalje, 52 dobavljača obavijestilo je HCPHS - Zavod za sjemenarstvo i rasadničarstvo o namjeri proizvodnje voćnih sadnica CAC kategorije i u 2017.g. proveden je nadzor kritičnih točaka proizvodnje kod svih. Prema Izvješćima dobavljača o proizvedenim količinama sadnica CAC kategorije u 2017.g. proizvedeno je ukupno 2.979.915 kom voćnih sadnica CAC kategorije.

Obradom rezultata stručnog nadzora voćnog sadnog materijala i primljenih Izvješća dobavljača o proizvedenim voćnim sadnicama CAC kategorije dobiveni su podaci o cjelokupnoj proizvodnji voćnih sadnica po vrstama, sortama i tipovima podloga u 2017.g.

Zadanim uvjetima kakvoće udovoljilo je 3.459.374 kom voćnih sadnica. U proizvodnji voćnih sadnica bila je 31 voćna vrsta, a najviše je zastupljena proizvodnja sadnica jabuka $38 \%$, sadnice lijeske $26 \%$, masline $5 \%$, višnje (+ maraske) $5 \%$, kruške $4 \%$, jagode $4 \%$, trešnje $3 \%$, šljive $3 \%$, agruma $2 \%$.

Od ukupne količine voćnih sadnica $14 \%$ su sadnice certificirane kategorije, $86 \%$ proizvodnje voćnih sadnica su sadnice CAC kategorije.

Što se tiče proizvodnje loznih cijepova, kod 15 dobavljača registriranih za djelatnost proizvodnje sadnog materijala, propisanim uvjetima kakvoće zadovoljilo je $1.920 .572 \mathrm{kom}$ loznih cijepova. U proizvodnji loznih cijepova bilo je 69 sorti vinove loze (13 stolnih sorti i 56 vinskih), najzastupljenija je 
sorta Graševina (31 \%), a zatim slijede: Plavac mali (7 \%), stolne sorte (6 \%), Pošip (6\%), Chardonnay (4 \%), Rajnski rizling (4\%), Sauvignon (4\%), Maraština (4 \%), Škrlet (3 \%) itd. Od ukupne proizvodnje $57 \%$ su lozni cijepovi kategorije certificirani, a $43 \%$ kategorije S-A.

\section{MATERIJAL I METODE}

Rezultati odnosno podaci izneseni u ovom radu dobiveni su obradom Prijava proizvodnje voćnih sadnica i loznih cijepova za stručni nadzor, odnosno obradom Obavijesti i Izvješća o proizvedenim količinama CAC sadnog materijala, te njihovom analizom. Navedene Prijave i Obavijesti proizvođači sadnog materijala dužni su, svake godine u kojoj zasnivaju proizvodnju, dostaviti Hrvatskom centru za poljoprivredu, hranu i selo - Zavodu za sjemenarstvo i rasadničarstvo, sukladno u Uvodu navedenim zakonskim aktima. Primljene prijave ondje se analiziraju, unose u bazu podataka te se po završenoj obradi podataka obavljaju nadzori na terenu. Po završetku nadzora, za materijal viših kategorija voćnih sadnica, te sve kategorije loznih cijepova, koji zadovoljavaju temeljne uvjete kakvoće, Centar izdaje Uvjerenja i takav se materijal može plasirati na tržište, pod uvjetom da su zadovoljeni i svi ostali zakonski kriteriji, prvenstveno misleći na fito - sanitarni status sadnog materijala, koji se također provjerava i prati tijekom proizvodne godine.

\section{REZULTATI I RASPRAVA}

\section{Voćne sadnice}

Proizvodnja voćnog sadnog materijala bilježi kroz godine različite stope kretanja proizvedenih količina.

Iz gore priloženog grafa vidljivo je kako je proizvodnja 2000. godine bila ispod 900.000 komada proizvedenih sadnica, a da bi u 2009. i 2010. godini, u zlatno doba hrvatskog rasadničarstva i poticanja proizvodnje i podizanja nasada, doživjela svoj vrhunac. Nakon toga slijedi pad proizvedenih količina voćnih sadnica, uz blagi trend rasta i oporavka rasadničarske proizvodnje u posljednje dvije godine. U 2017. godini proizvedeno je nešto manje od 3 i pol miljuna voćnih sadnica.

U 2017. godini ukupna prijavljena količina voćnih sadnica u proizvodnji iznoslila je 4.394.442 komada, od čega je 3.459.374 sadnica zadovoljilo temeljne uvjete kakvoće za stavljanje na tržište. 
K. Brus i sur.: Proizvodnja voćnog i loznog sadnog materijala u 2017. godini u Hrvatskoj

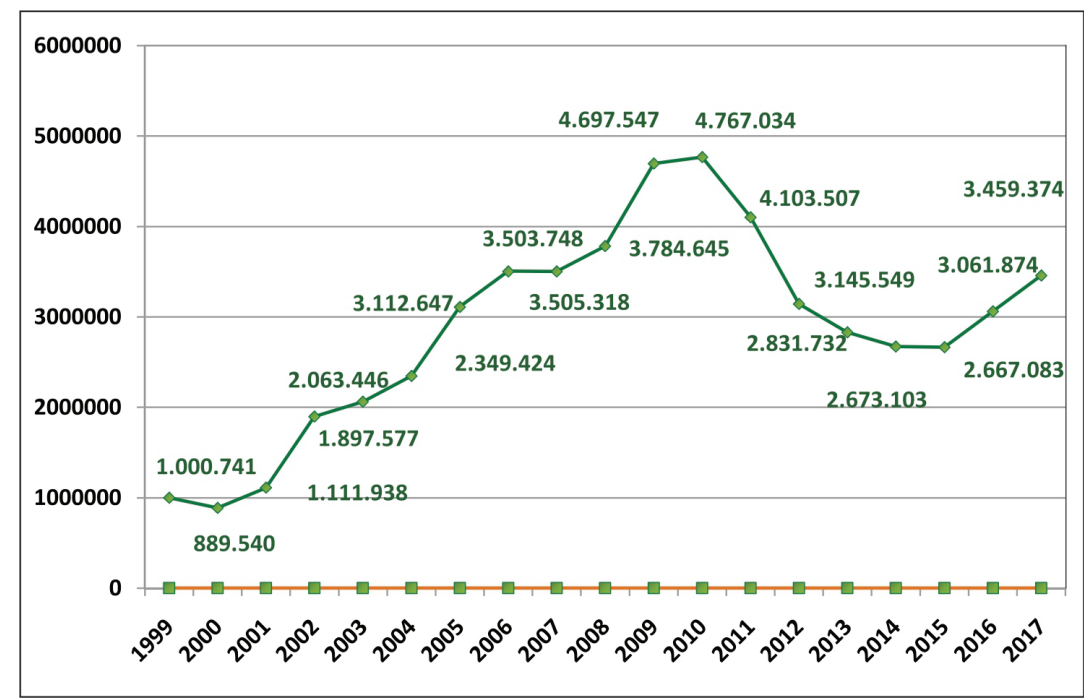

Graf 1: Kretanje proizvodnje voćnih sadnica 1999. - 2017. god.

Chart 1: Production of fruit seedlings 1999 - 2017

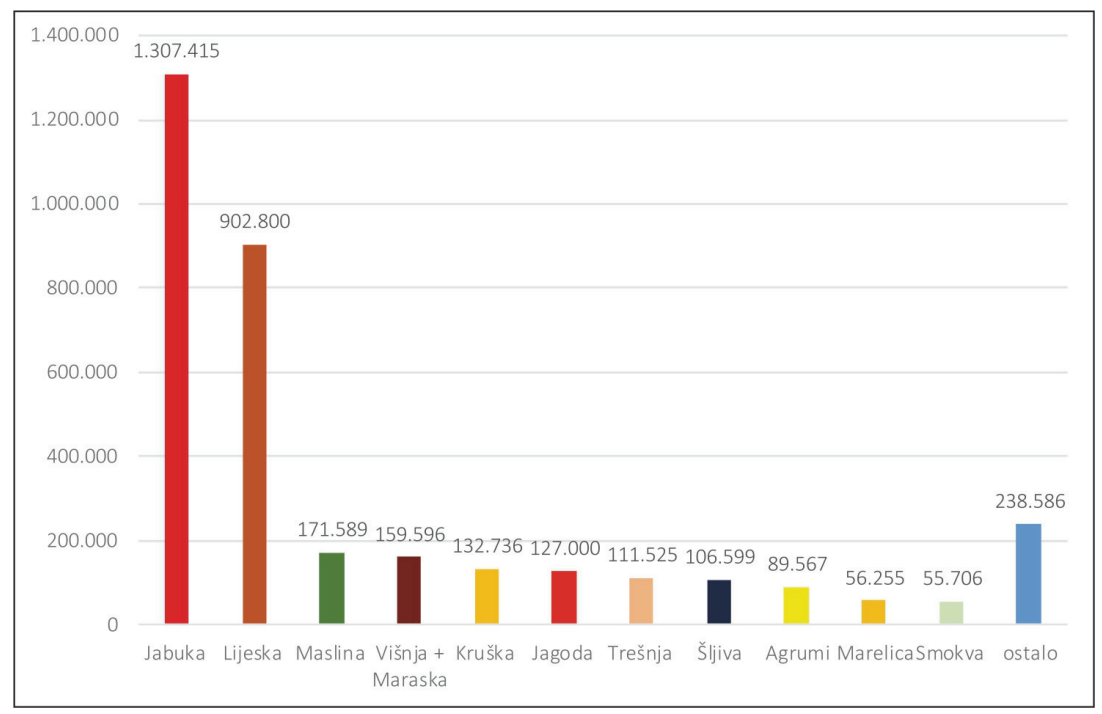

Graf 2: Količine po voćnim vrstama u proizvodnji voćnih sadnica u 2017. god. Chart 2: Quantities of fruit seedlings by varieties in 2017 
K. Brus i sur.: Proizvodnja voćnog i loznog sadnog materijala u 2017. godini u Hrvatskoj

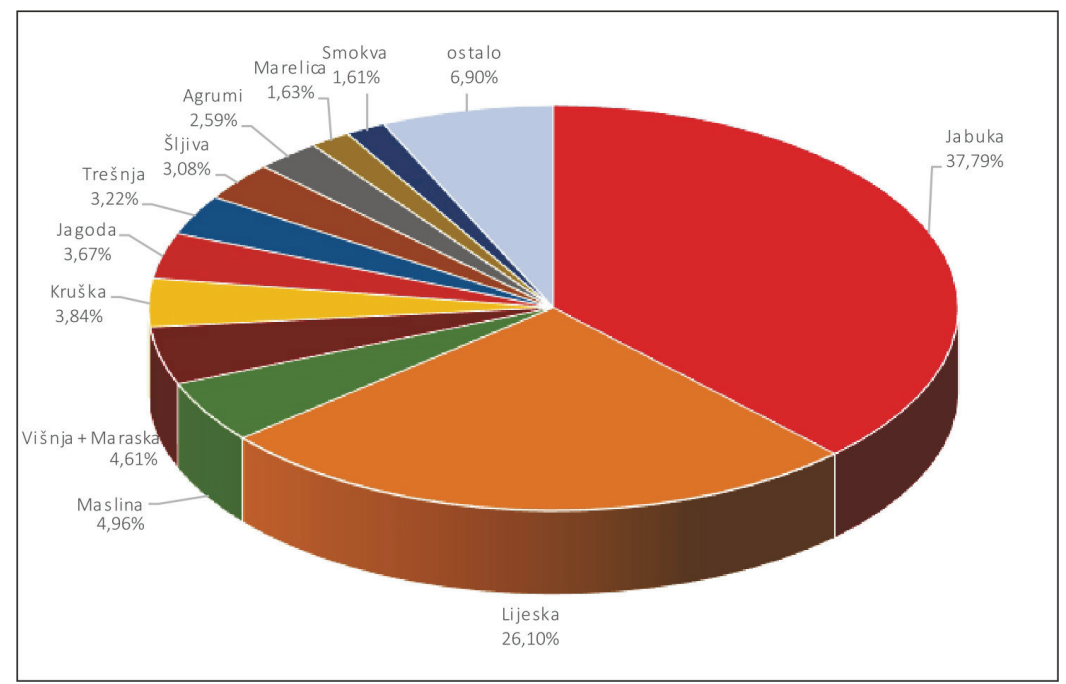

Graf 3: Zastupljenost pojedinih voćnih vrsta u proizvodnji voćnih sadnica u 2017. god.

Chart 3: Contribution of certain fruit varieties in production of fruit seedlings in 2017

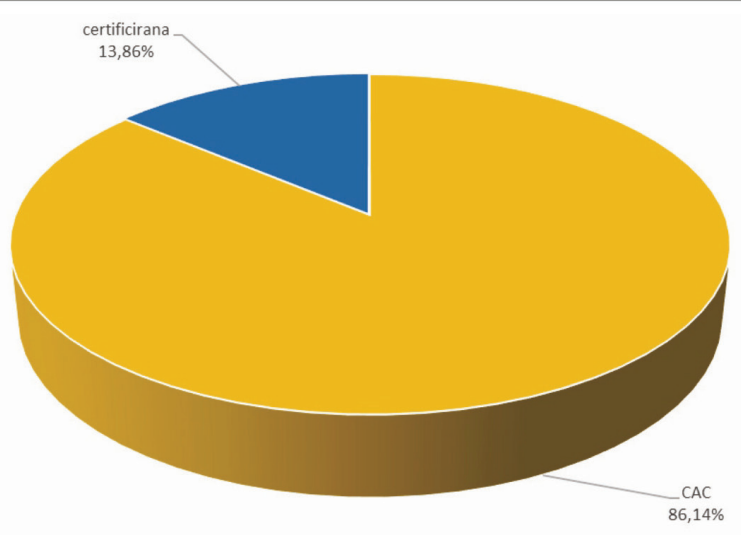

Graf 4: Kategorije proizvedenih voćnih sadnica u 2017. god.

Chart 4: Categories of produced fruit seedlings in 2017 
Što se tiče proizvodnje sadnog materijala viših kategorija, odnosno certificiranog sadnog materijala, u 2017. godini proizvodnja se odvijala kod 8 rasadničara i na 5 lokacija matičnih nasada te je proizvedeno 479.459 komada sadnica, što iznosi $14 \%$ od ukupne proizvodnje. Kada govorimo o standardnom materijalu, CAC kategorije, ta proizvodnja se odvijala kod 52 proizvođača sadnog materijala kod kojih je proizvedeno ukupno 2.979.915 sadnica, odnosno $86 \%$ ukupne proizvodnje.

Ako usporedimo proizvedenu količinu certificiranih voćnih sadnica u 2016. godini, kada je ona iznosila $22 \%$, u 2017. zabilježen je pad proizvodnje sadnica viših kategorija za oko $8 \%$.

Po pitanju strukture proizvodnje voćnih sadnica, u 2107. godini, a kao i u prijašnjim godinama, najzastupljenija voćna vrsta je jabuka. Od ostalih voćnih vrsta zastupljenija je još proizvodnja sadnica lijeske, dok su ostale voćne vrste zastupljene u manjoj mjeri i njihov udio u ukupnoj proizvodnji kreće se od 3 do $5 \%$.

Ulaskom Republike Hrvatske u Europsku uniju kao punopravne članice, Republika Hrvatska preuzela je i obvezu implementiranja Europskih direktiva u nacionalno zakonodavstvo. Slijedom toga, od 1. veljače 2017. godine na snagu je stupio novi Pravilnik o stavljanju na tržište reprodukcijskog sadnog materijala i sadnica namijenjenih za proizvodnju voća, a u koji su implementirane direktive Europske unije (2008/90/EZ, 2014/96/EU, 2014/97/EU, 2014/98/EU).

Najveća promjena koju je donio novi pravilnik (Pravilnik o stavljanju na tržište reprodukcijskog sadnog materijala i sadnica namijenjenih za proizvodnju voća NN 09/17) odnosi se na podjelu nadzora proizvodnje na stručni nadzor i nadzor kritičnih točaka u proizvodnji. Stručni nadzor vrši se nad višim kategorijama sadnog materijala (certificirana, osnovna i pred osnovna kategorija sadnog materijala) dok se nadzor kritičnih točaka vrši nad svim kategorijama sadnog materijala, uključujući i standardnu (CAC) kategoriju. Iz navedene promjene proizlazi kako novim pravilnikom sadni materijal CAC kategorije više nije u sustavu stručnog nadzora već je isključivo pod nadzorom proizvođača sadnog materijala koji ga proizvodi, a jedan oblik kontrole proizvodnje tog materijala ostavljen je za nadzor kritičnih točaka u proizvodnji.

Obveze proizvođača vezane uz evidenciju o utvrđivanju i praćenju kritičnih točaka $(\mathrm{KT}) \mathrm{u}$ proizvodnji i nadzor dobavljača vezan uz KT propisan je u članku 8. Pravilnika o voćnom sadnom materijalu.

Evidencija KT treba sadržavati podatke o:

1. Mjestu i broju biljaka (naziv lokacije i količina biljaka u proizvodnji); 
K. Brus i sur.: Proizvodnja voćnog i loznog sadnog materijala u 2017. godini u Hrvatskoj

2. Razdoblju njihovog uzgoja (podaci o terminima sadnje, cijepljenja, vađenja..);

3. Postupcima razmnožavanja (vegetativno, generativno, korištene metode cijepljenja);

4. Postupcima pakiranja, skladištenja i prijevoza;

5. Provođenju agrotehničkih mjera (zaštita i ostale radne operacije);

6. Reprodukcijskom materijalu u svrhu dokazivanja njegovog porijekla (omogućiti uvid u račune i otpremnice za kupljeni tuđi reprodukcijski materijal korišten u proizvodnji);

7. Održavanju sorti s Popisa sorti voćnih vrsta (vođenje i ažuriranje evidencije o vlastitim matičnim biljkama);

8. Uzorkovanju i analizi na prisutnost štetnih organizama (omogućiti uvid u zapisnike o uzorkovanju i rezultate napravljenih analiza).

Proizvođač je također obvezan osigurati da različite partije sadnog materijala budu odvojene, voditi evidenciju o inspekcijskim pregledima na terenu, uzorkovanju i testiranju, te čuvati svu evidenciju o određenoj proizvodnji najmanje tri godine.

Novim pravilnikom također je reguliran i status malih proizvođača - to su proizvođači koji proizvode voćne sadnice u količini manjoj od 100 komada sadnica i oni se nisu dužni upisat u Upisnik dobavljača poljoprivrednog sadnog materijala koji se vodi pri Ministarstvu poljoprivrede, te mogu u okviru lokalne cirkulacije tržiti sorte koje nisu od komercijalne važnosti i nisu na Popisu sorti voćnih vrsta, pod uvjetom da ih prodaju neprofesionalnim korisnicima.

\section{Lozni cijepovi}

Proizvodnja loznih cijepova u Republici Hrvatskoj u proteklih sedam godina bilježi stalan i drastičan pad proizvedenih količina, sa vrlo blagom tendencijom oporavka u posljednje dvije godine.

U 2017. godini ukupna prijavljena količina loznih cijepova u proizvodnji iznoslila je 3.057.226 komada, od čega je 1.920 .572 komada loznih cijepova zadovoljilo temeljne uvjete kakvoće za stavljanje na tržište.

Proizvodnja sadnog materijala loznih cijepova odvijala se kod 15 rasadničara i na 38 lokacija matičnih nasada. Strukturu proizvedenog sadnog materijala činile su 13 stolnih i 56 vinskih sorti, a $57 \%$ materijala je certificirane kategorije $\mathrm{i}$ to je pozitivan trend udjela certificirane kategorije sadnog materijala u ukupno proizvedenim količinama, i iz godine u godinu se povećava pa je tako u 2014. godini udio certificiranog materijala bio $33 \%$, u 2015. godini $41 \%$, u 2016. godini $48 \%$. 
K. Brus i sur.: Proizvodnja voćnog i loznog sadnog materijala u 2017. godini u Hrvatskoj

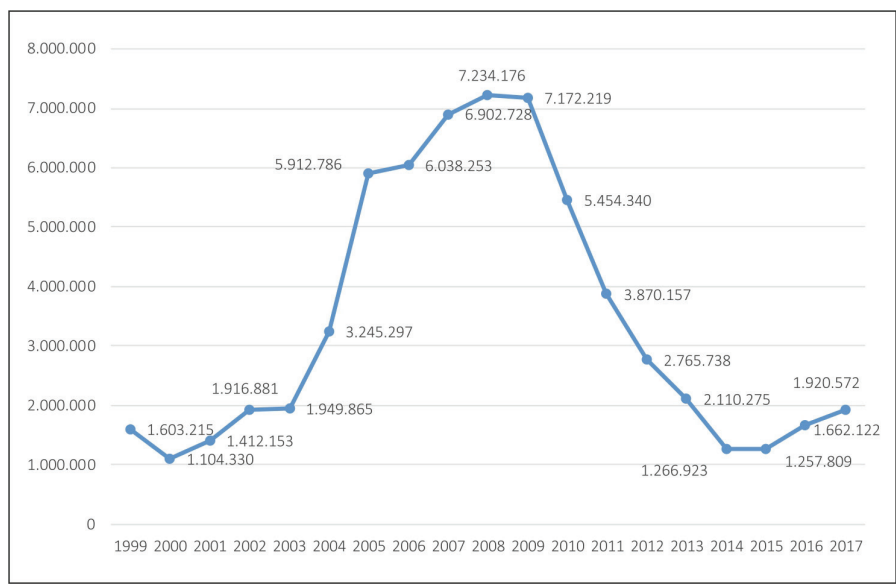

Graf 5: Kretanje proizvodnje loznih cijepova 1999. - 2017. god.

\section{Chart 5: Production of vine seedlings 1999 - 2017}

Od sorti u proizvodnji, najzastupljenija je i dalje Graševina koja pokriva gotovo 1/3 ukupno proizvedenih loznih cijepva, dok su ostale sorte zastupljene u manjim količinama bez da se neka posebno ističe. Najznačajnije sorte koje se nalaze u proizvodnji, osim Graševine su Plavac mali, Pošip, Chardonay, Rajnski rizling, Sauvignon, Maraština, Škrlet, Traminac, Merlot i Syrah. Prikaz proizvedenih količina pojedinih sorti je u sljedećem grafu.

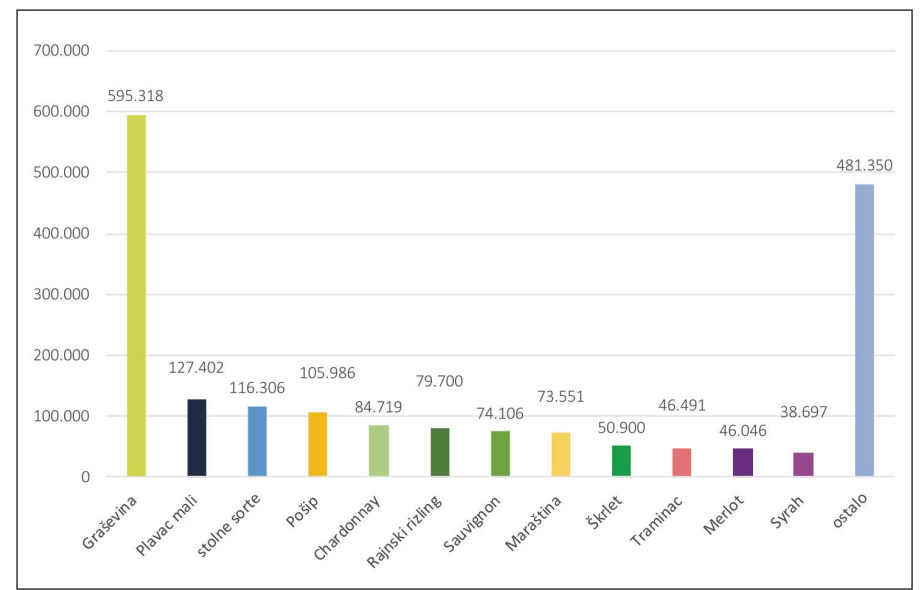

Graf 6: Količine po sortama u proizvodnji loznih cijepova u 2017. god.

Chart 6: Quantities of produced vine seedlings in 2017 by type 
K. Brus i sur.: Proizvodnja voćnog i loznog sadnog materijala u 2017. godini u Hrvatskoj

Što se tiče zastupljenosti pojedinih vrsta podloga, najzastupljenije podloge $\mathrm{u}$ proizvodnji loznih cijepova bile su SO4, s preko 50 \% udjela, te Kober 5BB sa $20 \%$.

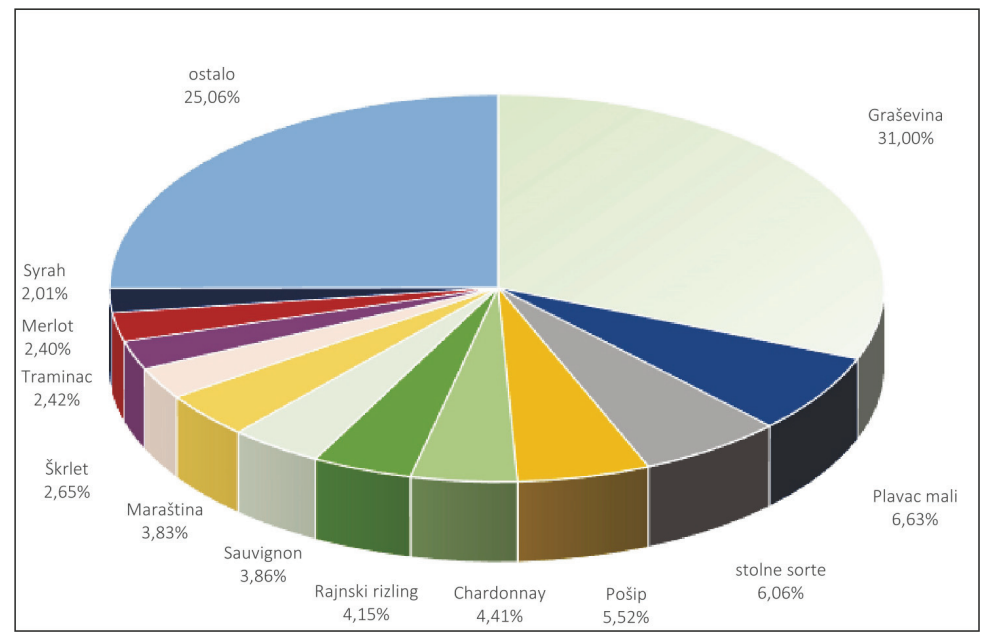

Graf 7: Zastupljenost sorti u proizvodnji loznih cijepova u 2017. god.

Chart 7: Contribution of certain vine seedlings in 2017 by type

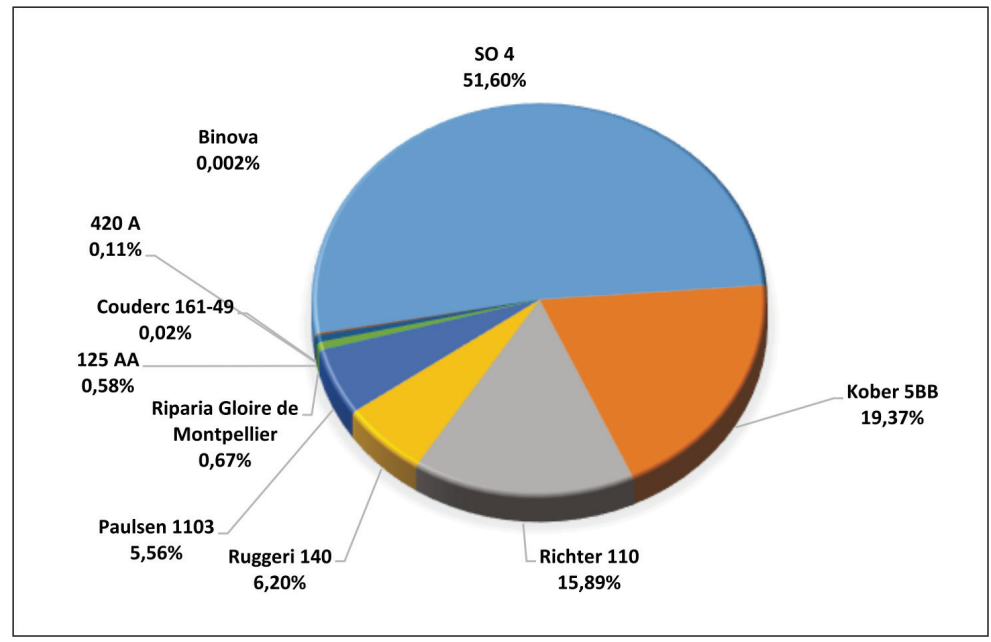

Graf 8: Podloge u proizvodnji loznih cijepova u 2017. god.

Chart 8: Rootstocks in vine seedlings production in 2017 
K. Brus i sur.: Proizvodnja voćnog i loznog sadnog materijala u 2017. godini u Hrvatskoj

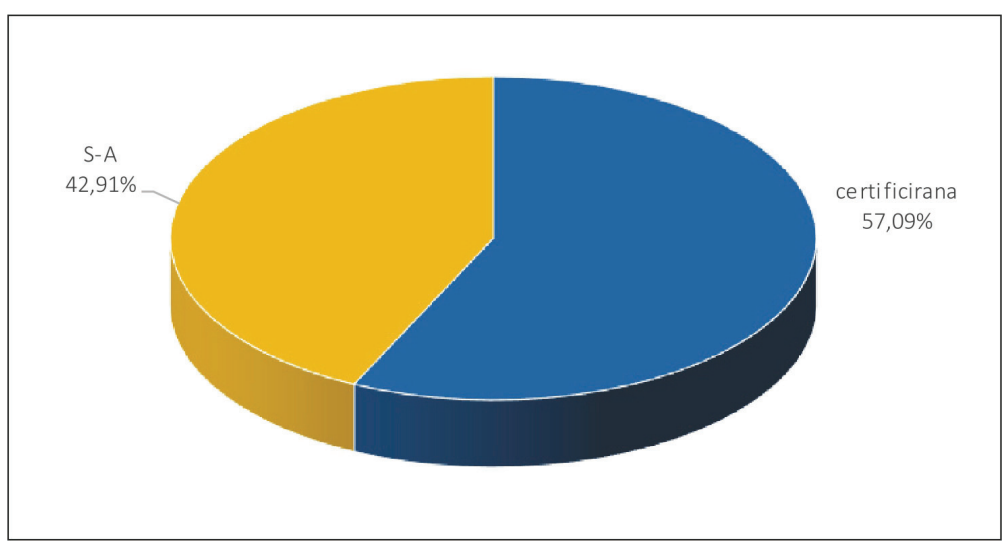

Graf 9: Kategorije proizvedenih loznih cijepova u 2017. god.

Chart 9: Categories of produced vine seedlings in 2017

\section{ZAKLJUČAK}

Republika Hrvatska ima dugu tradiciju kako voćarstva i vinogradarstva, tako i polazišne djelatnosti, voćnog i loznog rasadničarstva. Kako smo mogli vidjeti iz gore navedenih grafova i teksta, količine proizvedenih voćnih sadnica i loznih cijepova variraju iz godine u godinu. Svojevrsnu renesansu hrvatsko rasadničarstvo doživjelo je u periodu od 2008. do 2011. godine, u doba poticanja rasadničarske i voćarske proizvodnje, a završetkom toga razdoblja, proizvedene količine su u konstantnom padu. U 2015. godini, proizvedene količine su zabilježile minimalne vrijednosti u zadnjih desetak godina, da bi se u 2016. i 2017. godini osjetila naznaka stagnacije negativnog trenda i blago povećanje proizvedenih količina. Stoga nam ne preostaje ništa drugo nego nadati se da će tržište prepoznati vrijednost domaćeg sadnog materijala, nad onim što se može dobaviti iz ostalih zemalja članica, te kako će i za ovu granu hrvatske poljoprivrede ponovno doći neki bolji dani.

\section{IZVOR}

Hrvatski centar za poljoprivredu, hranu i selo - Zavod za sjemenarstvo i rasadničarstvo;

https://narodne-novine.nn.hr/clanci/sluzbeni/2005_11_140_2644.html; 
https://narodne-novine.nn.hr/clanci/sluzbeni/2008_03_35_1143.html; https://narodne-novine.nn.hr/clanci/sluzbeni/2011_05_55_1199.html; https://narodne-novine.nn.hr/clanci/sluzbeni/2014_02_14_284.html; https://narodne-novine.nn.hr/clanci/sluzbeni/2017_02_9_275.html; https://narodne-novine.nn.hr/clanci/sluzbeni/2006_12_133_3024.html; https://narodne-novine.nn.hr/clanci/sluzbeni/2010_05_67_2067.html; https://narodne-novine.nn.hr/clanci/sluzbeni/2011_03_30_653.html; https://narodne-novine.nn.hr/clanci/sluzbeni/2013_06_77_1555.html; https://narodne-novine.nn.hr/clanci/sluzbeni/2009_12_144_3520.html; https://narodne-novine.nn.hr/clanci/sluzbeni/2011_03_30_652.html; https://narodne-novine.nn.hr/clanci/sluzbeni/2011_05_50_1123.html; https://eur-lex.europa.eu/legalcontent/HR/TXT/PDF/?uri=CELEX:32008L0090\&from=HR; https://eur-lex.europa.eu/legalcontent/HR/TXT/PDF/?uri=CELEX:32014L0096\&qid=1547720242397\&fr $\mathrm{om}=\mathrm{HR}$;

https://eur-lex.europa.eu/legalcontent/HR/TXT/PDF/?uri=CELEX:32014L0097\&qid=1547720319354\&fr $\mathrm{om}=\mathrm{HR}$;

https://eur-lex.europa.eu/legalcontent/HR/TXT/PDF/?uri=CELEX:32014L0098\&qid=1547720374904\&fr $\mathrm{om}=\mathrm{HR}$.

\section{Author's address - Adresa autora:}

Krunoslav Brus, e- mail: krunsolav.brus@hcphs.hr, Kristina Horvat - Budimir

Hrvatski centar za poljoprivredu hranu i selo, Zavod za sjemenarstvo i rasadničarstvo, Usorska 19, Brijest, 31000 Osijek, Hrvatska 
